\title{
С.В. Лобода*
}

Тихоокеанский научно-исследовательский рыбохозяйственный центр, 690091, г. Владивосток, пер. Шевченко, 4

\section{НЕКОТОРЫЕ РЕЗУЛЬТАТЫ ИССЛЕДОВАНИЙ ТИХООКЕАНСКОЙ СЕЛЬДИ В ПЕРИОД ЗИМНЕ-ВЕСЕННЕГО ПРОМЫСЛА В ОХОТСКОМ МОРЕ}

\begin{abstract}
Представлен краткий обзор результатов исследований тихоокеанской сельди в период зимне-весеннего промысла в Охотском море в 2017 г. Исследована возможность целевой обработки первичных материалов, собранных научными наблюдателями на промысловых судах. Представлены метод и результаты оценки численности и биомассы сельди в двух промысловых подзонах Охотского моря на основании данных наблюдений на промысле. С учетом площадей основных промысловых районов и плотностей распределения рыб суммарная величина запаса для принятых во внимание регионов составила 1854,92 тыс. т и 7390,36 млн экз. рыб. Из них почти две трети биомассы сельди (64,6 \%) было сосредоточено в Северо-Охотоморской подзоне. В 2017 г. более 90 \% от расчетной биомассы и численности рыб в период добычи в Северо-Охотоморской и Западно-Камчатской подзонах составляла сельдь промысловых размеров. Промыслом фактически не учитывалась значительная часть неполовозрелой молоди. Результаты проведенных в 2017 г. исследований на промысловых судах показали, что в дальнейшем подобные методы работ можно использовать как дополнительные для контроля состояния промысловых запасов сельди в Охотском море.

Ключевые слова: Охотское море, сельдь, промысел, распределение, оценка запаса, биомасса, промысловый запас.
\end{abstract}

DOI: 10.26428/1606-9919-2018-195-140-145.

Loboda S.V. Some results of the pacific herring studies in the period of winter-spring fishery in the Okhotsk Sea // Izv. TINRO. - 2018. - Vol. 195. - P. 140-145.

Pacific herring stock was evaluated for two fishery districts in the Okhotsk Sea (North-Okhotsk and West-Kamchatka subzones) on the data collected during winter-spring fishery in 2017. The method of evaluation is described, quality of the materials collected aboard commercial fishing vessels is discussed, and the assessments are presented. Taking into account the areas of the districts and density of fish distribution, the stock of herring is counted as $1854.92 \cdot 10^{3} \mathrm{t}\left(7390.36 \cdot 10^{6} \mathrm{ind}\right.$.), mostly within the North-Okhotsk subzone ( $64.6 \%$ by biomass). More than $90 \%$ of this stock was formed by herring of commercial size that means that its juveniles were not counted properly by commercial catches. So, the stock assessment on the data of commercial catches could be used as additional method of the commercial stock monitoring, beyond the data of scientific surveys.

Key words: Okhotsk Sea, herring, fishery, fish distribution, stock assessment, biomass, commercial stock.

\section{Введение}

Тихоокеанская сельдь Clupea pallasii - один из важнейших представителей промысловой ихтиофауны Охотского моря. По своей значимости в экосистеме северной

* Лобода Сергей Владимирович, научный сотрудник, е-mail: sergey.loboda@tinro-center.ru. Loboda Sergey V., researcher, e-mail: sergey.loboda@tinro-center.ru. 
части Охотского моря сельдь уступает только минтаю (Шунтов, 1998). На Дальневосточном бассейне тихоокеанская сельдь всегда была одним из важнейших объектов промысла, занимая по объемам вылова второе место после минтая. В настоящее время величина запасов сельди в Охотском море находится на хорошем промысловом уровне и позволяет добывать ее практически по потребности. Уровень освоения запасов сельди определяется целым рядом факторов, в большинстве случаев не связанных с состоянием запасов. В последние годы (2011-2017) степень освоения ОДУ охотской сельди колеблется в пределах 82,2-97,4 \%, ОДУ/РВ гижигинско-камчатской популяции сельди за тот же период лет осваивались от 6,5 до 113,0 \%*.

Основная часть информации для обеспечения ОДУ сельди традиционно собирается непосредственно на нерестилищах (Науменко, 2001; Смирнов, 2009; Нагульная сельдь, 2017*). Кроме того, используются данные научно-исследовательских траловых съемок и результаты наблюдений на промысловых судах.

С развитием крупномасштабного тралового промысла всегда сохранялся интерес к возможностям определения величины запасов сельди в районах ее промысла. Подобные исследования необходимы для определения и уточнения динамики различных показателей промысловых скоплений, а также сбора первичных материалов для подготовки прогнозов различной заблаговременности. В современных экономических условиях проведение таких специализированных исследований на научно-исследовательских судах не всегда возможно. Изучение данных наблюдателей на промысле сельди показало, что собираемые материалы позволяют в какой-то степени решать возникающие вопросы. Предполагается, что объемы накапливаемых за период добычи сельди научных материалов, могут быть использованы не только для определения размерно-возрастных и некоторых других биологических характеристик промысловых скоплений рыб, но и для определения показателей плотности скоплений и иных дополнительных параметров.

Цель работы - изучить возможность оценки запасов и биологического состояния тихоокеанской сельди в промысловых районах Охотского моря в зимне-весенний период по данным научных наблюдений на промысловых судах.

\section{Материалы и методы}

В работе использованы данные, собранные на 6 промысловых судах типа БМРТ, добывавших сельдь в период с января по апрель 2017 г. в Северо-Охотоморской (125 учетных тралений) и Западно-Камчатской (25 учетных тралений) промысловых подзонах. На каждом из судов научным сотрудником проводился сбор стандартной промысловой и научно-исследовательской информации. Собранные материалы включали в себя данные по промысловым показателям тралений (координаты, скорость тралений, горизонтальное и вертикальное раскрытие трала, улов на усилие, улов на час траления и пр.), биостатистические данные по объектам промысла (размеры, масса, соотношение полов и др.).

Так как траления выполнялись на различных судах, с различными типами тралов и параметрами тралений (при этом горизонтальное раскрытие трала только у одного судна в зависимости от условий траления могло изменяться от 70 до 120 м, а скорость траления - от 3,0 до 4,5 уз), для построения карт распределения сельди, величины уловов по районам и всех последующих расчетов использовался показатель плотности распределения рыб на 1 км². Этот показатель позволяет исключать влияние технических и прочих особенностей отдельного судна на представление общей картины пространственной дифференциации и величины концентраций скоплений сельди.

Все расчеты выполнялись по близкой к единой методической схеме, многократно описанной в статьях различных исследователей (Шунтов и др., 1998; Волвенко, 1999; Мельников, 2002; и др.), за исключением некоторых специфических моментов, представленных ниже.

* Нагульная сельдь 2017 (путинный прогноз). Владивосток: ТИНРО-центр, 2017. 77 с. 
Траления в пределах обследованных районов располагались неравномерно в связи с изменчивостью (неоднородностью) распределения сельди, кроме того, существенно различались величины уловов. В этой ситуации наиболее целесообразным оказалось определять расчетные численность и биомассу сельди отдельно для площадей, принадлежащих каждому конкретному тралению (рис. 1), а затем суммировать эти величины по тем или иным районам в целом. Для этого акватория каждого района была разбита на «микрорайоны» по количеству тралений. Площадь, принадлежащая каждому тралению, была определена с использованием площадей многоугольников, соответствующих каждому отдельному тралению (ячейки Дирхле-Вороного или полигоны Тиссена). Таким образом, с увеличением частоты тралений уменьшается принадлежащая каждому из них площадь, на которую экстраполируется результат. Этим ограничивается ошибка за счет случайных высоких и низких уловов, более адекватно оценивается «вклад» в результаты по районам с изменчивыми уловами, иначе говоря, «вклад» каждого траления в суммарный результат «взвешивается» через принадлежащую данному тралению площадь. Таким образом, при изменении частоты тралений регулируется «вес» каждого из них при неоднородной сетке распределения уловов. В случае совпадения точек тралений использовались средние показатели лова.

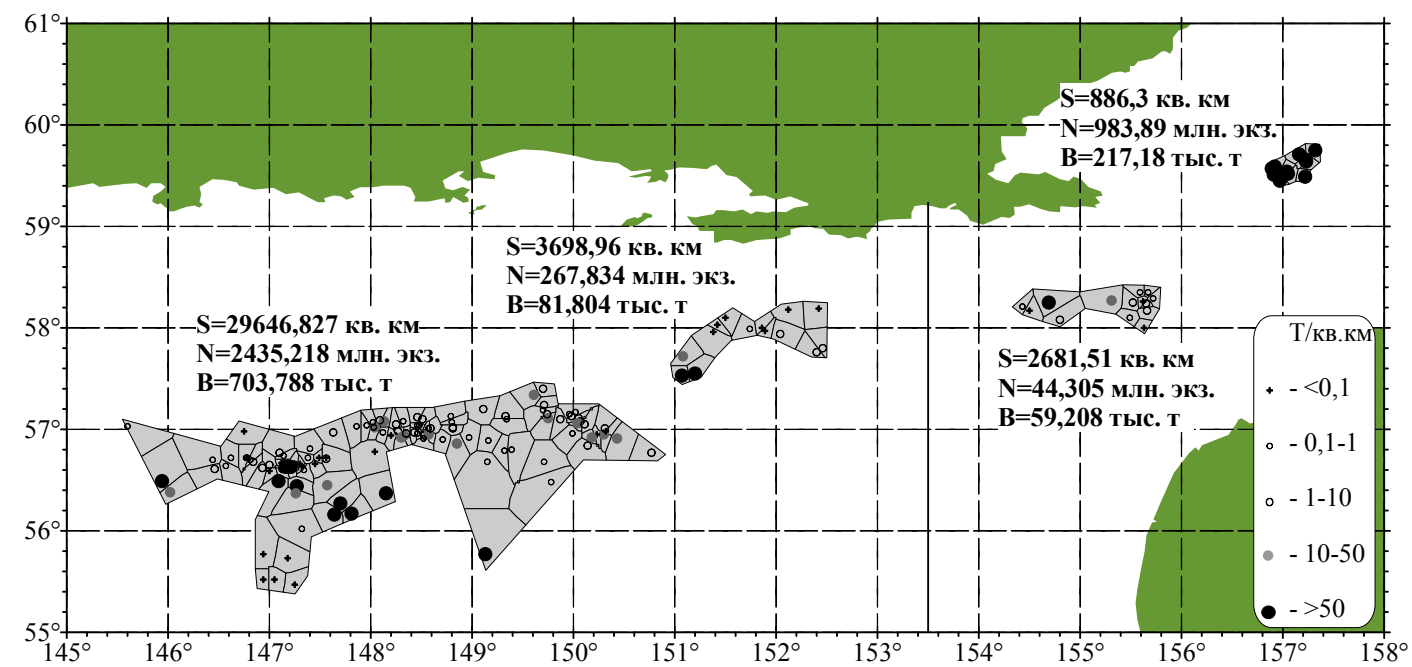

Рис. 1. Распределение биомассы (т/км²) сельди по данным тралений промысловых судов в Северо-Охотоморской и Западно-Камчатской подзонах Охотского моря в период зимне-весеннего промысла 2017 г. и положение ячеек Дирхле-Вороного. Сплошные линии - границы промысловых районов. Здесь и далее $S$ - площадь, $N$ - численность, $B$ - биомасса

Fig. 1. Spatial distribution of herring biomass $\left(\mathrm{t} / \mathrm{km}^{2}\right)$ on the data of commercial trawl catches in the North-Okhotsk and West-Kamchatka subzones in winter-spring fishery season in 2017 and Dirhle-Voronoi cells. Solid lines — boundaries of fishery districts. Hereinafter: $S$ - area, $N$ - abundance, $B$ - biomass

Пересчет размерного ряда на численность особей производился для «микрорайона» каждого конкретного траления. Поскольку в расчете численности для каждого «микрорайона» учитывается величина улова, площадь облова и площадь обследованного района, принадлежащая каждому тралению, то и каждый размерный ряд оказывается «взвешенным» по этим показателям. Преобразованные таким образом размерные ряды по каждому тралению суммировались по районам для получения обобщенных размерных рядов численности. Фактически обобщение промеров повторяет процедуру расчета численности по районам, и поэтому полученные значения численности и суммарные размерные ряды соответствуют друг другу. Таким образом, описанные действия позволили «разложить» расчетную численность по размерному ряду. 


\section{Результаты и их обсуждение}

Исследовательские работы проводились в Северо-Охотоморской и Западно-Камчатской подзонах Охотского моря. По итогам работ первоначально было выделено по два локальных участка в каждой подзоне, результаты наблюдений в которых могли быть использованы для расчетов (рис. 1). Необходимо было оценить, насколько точно полученная картина пространственной дифференциации скоплений рыб соответствует общей картине распространения сельди по промысловому району. Для этого были построены карты плотностей распределения сельди по обследованным акваториям и суточному вылову промысловыми судами объекта исследований (рис. 2, 3). За основные промысловые районы (для которых в дальнейшем проводились расчеты) были приняты акватории промысла, на которых за весь период наблюдений было выполнено не менее 3-5 результативных промысловых операций с величиною вылова от 5 т и более сельди в сутки (рис. 3). Все остальные данные по вылову сельди за пределами указанного региона (основная область распределения выловов заштрихована на рис. 3) к промысловому району не были отнесены, так как величины вылова там были незначительными и, скорее всего, сельдь присутствовала в уловах как прилов при промысле минтая.

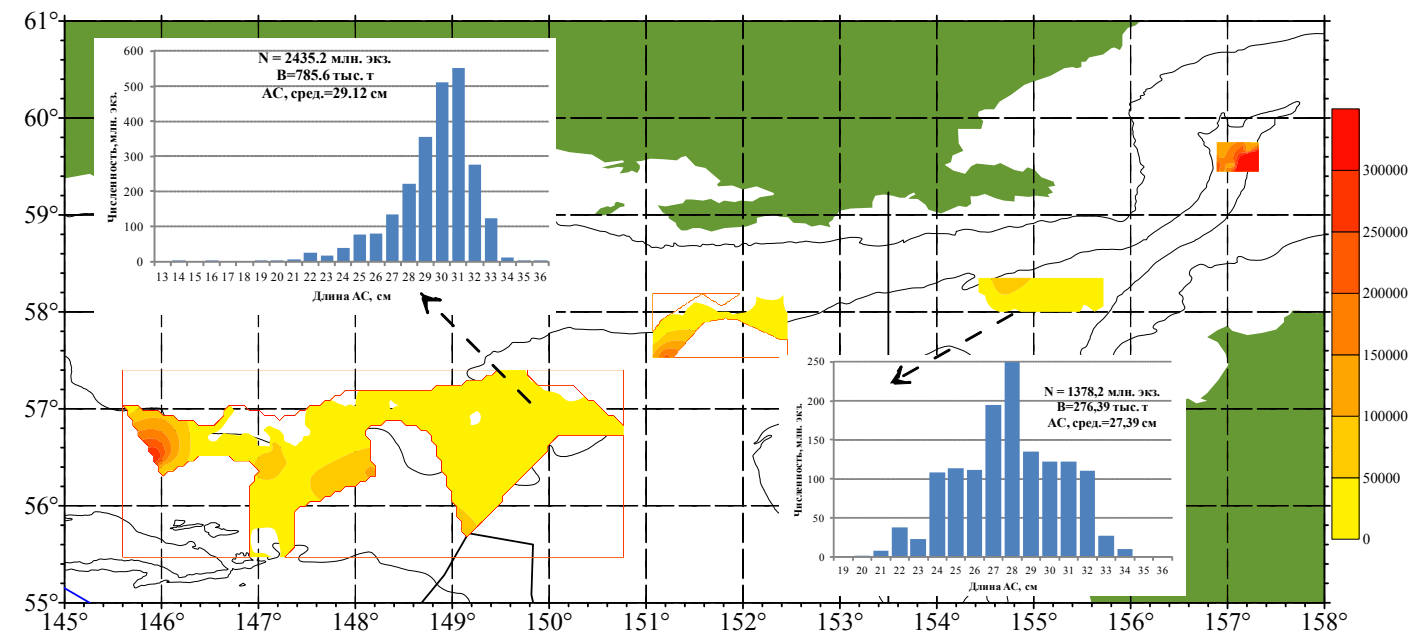

Рис. 2. Схема пространственного распределения плотности $\left(\mathrm{T} / \mathrm{KM}^{2}\right)$ скоплений и размерный состав уловов сельди по данным наблюдений на промысловых судах в Северо-Охотоморской и Западно-Камчатской подзонах Охотского моря в период зимне-весеннего промысла 2017 г.

Fig. 2. Spatial distribution of biomass $\left(\mathrm{t} / \mathrm{km}^{2}\right)$ and size composition of herring on the data of commercial trawl catches in the North-Okhotsk and West-Kamchatka subzones in winter-spring fishery season in 2017

Как показало такое сравнение, данные, собранные наблюдателями на промысловых судах, достаточно корректно описывают общую ситуацию распределения рыб в промысловом районе и пространственные изменения величины плотности скоплений сельди на интересующих нас акваториях Охотского моря.

Общая площадь двух обследованных районов в Западно-Камчатской подзоне равнялась 3567,8 км² $^{2}$ расчетные численность и биомасса сельди были определены соответственно в 1378,2 млн экз. и 276,4 тыс. т (см. рис. 1). Средняя плотность распределения рыб по изученному региону составила 386,3 тыс. экз./км ${ }^{2}$ и 77,5 т/км². Эти показатели и были приняты как средние величины для расчета обилия сельди в основном промысловом районе Западно-Камчатской подзоны. По нашим оценкам, площадь этого района составила 8474 км². Численность и биомасса сельди соответственно были определены в 3273,42 млн экз. и 656,47 тыс. т.

В Северо-Охотоморской подзоне суммарная обследованная площадь была значительно больше и равнялась 33345,79 км² $^{2}$ расчетные численность и биомасса сельди составили соответственно 2703,05 млн экз. и 785,59 тыс. т (рис. 1). Средняя плотность 


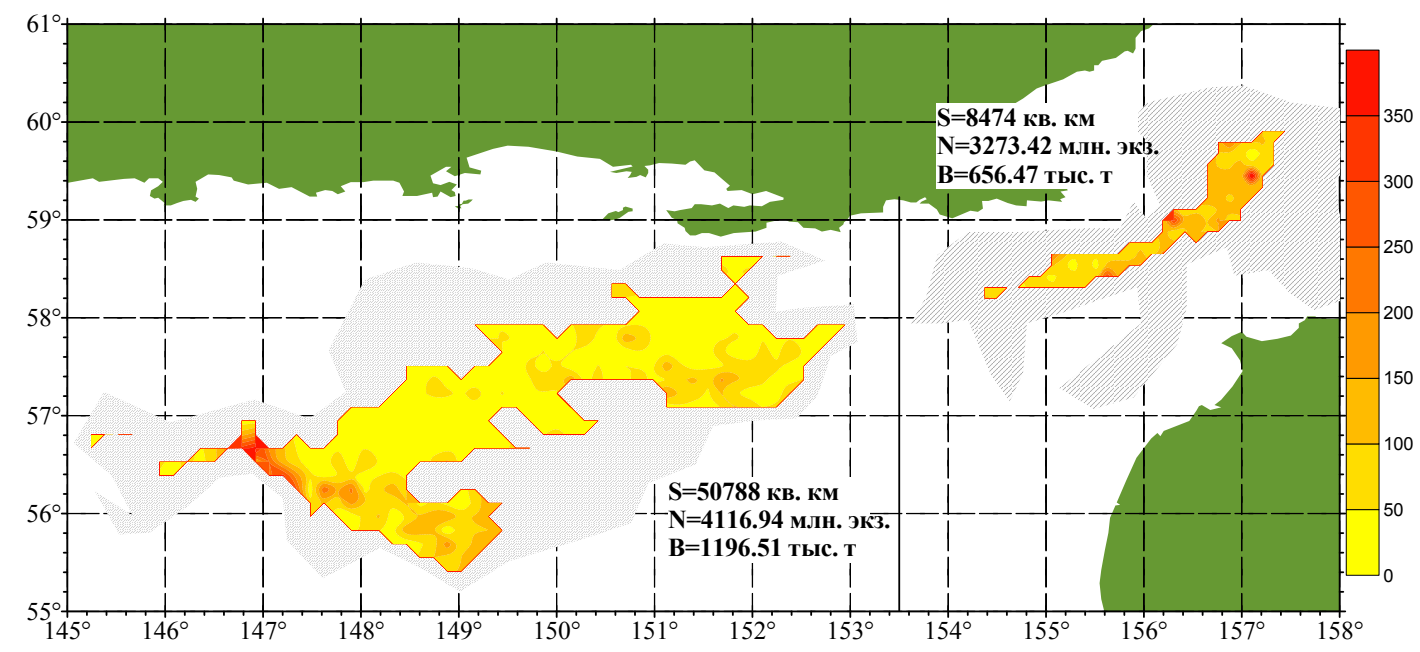

Рис. 3. Схема пространственного распределения величин суточного вылова (т) сельди промысловыми судами в Северо-Охотоморской и Западно-Камчатской подзонах Охотского моря в период зимне-весеннего промысла 2017 г.

Fig. 3. Spatial distribution of daily catch of herring (t) by commercial vessels in the North-Okhotsk and West-Kamchatka subzones in winter-spring fishery season in 2017

распределения рыб по региону составила 81,06 тыс. экз./км² и 23,56 т/км². Площадь основного промыслового района была определена в 50788 км² $^{2}$ Численность и биомасса сельди соответственно составили 4116,94 млн экз. и 1196,51 тыс. т.

Данные, собранные в период исследований, позволяют также иметь представление о биологических характеристиках сельди, отмечавшейся в уловах промысловых тралений.

Так, на обследованной акватории Западно-Камчатской подзоны размерный ряд сельди (рис. 2) варьировал в интервале длин (по АС) от 14 до 36 см (средняя длина - 27,39 см, средняя масса - 0,21 кг). Основная масса рыб $(92,1 \%)$ имела размеры 24-32 см. Заметно выделялась одна модальная группа - 27-28 см. Практически вся эта группа рыб длиной более 24 см и составляла промысловый запас сельди в подзоне весной 2017 г.

В Северо-Охотоморской подзоне диапазон размерного ряда был аналогичным (при средней длине рыб 29,12 см, средней массе 0,289 кг), но по сравнению с промысловыми районами у западной Камчатки модальная группа была заметно смещена вправо и в основном (83,8 \%) сельдь имела длину 28-33 см. В целом более 96 \% рыб достигали промысловых размеров.

\section{Выводы}

По данным научно-исследовательских наблюдений на промысловых судах в период зимне-весеннего промысла минтая и сельди суммарная биомасса тихоокеанской сельди в пределах обследованных акваторий северной части Охотского моря была оценена в 1061,98 тыс. т, численность - 3731,247 млн экз. С учетом площадей основных промысловых районов и плотностей распределения рыб суммарная величина запаса для принятых во внимание регионов составила 1854,92 тыс. т и 7390,36 млн экз. рыб. Из них почти две трети биомассы сельди (64,6 \%) было сосредоточено в СевероОхотоморской подзоне.

По результатам биологических исследований, в 2017 г. более 90 \% от расчетной биомассы и численности рыб в период добычи в Северо-Охотоморской и Западно-Камчатской подзонах составляла сельдь промысловых размеров. Промыслом фактически не учитывалась значительная часть неполовозрелой молоди, область распространения которой в этот период года обычно не совпадает с ареалом половозрелых особей. К 
тому же в случае большого прилова рыб непромысловых размеров промысловые суда покидают район.

Результаты проведенных в 2017 г. исследований на промысловых судах показали, что в дальнейшем подобные методы работ возможно использовать как дополнительные для контроля состояния промысловых запасов сельди в Охотском море. Кроме того, такие исследования ощутимо дополняют научные материалы по размерно-возрастной структуре добываемой на промысле сельди и многой другой биологической информации, используемой для прогнозирования ОДУ и РВ по сельди в регионе.

\section{Список литературы}

Волвенко И.В. Некоторые алгоритмы обработки данных по обилию и размерно-весовому составу уловов // Изв. ТИНРО. - 1999. — Т. 126. — С. 177-195.

Мельников И.В. Результаты оценки запаса сельди в северной части Охотского моря по траловым съемкам 2000 г. // Изв. ТИНРО. - 2002. - Т. 130. - С. 1142-1158.

Науменко Н.И. Биология и промысел морских сельдей Дальнего Востока : моногр. Петропавловск-Камчатский : Камчат. печат. двор, 2001. - 330 с.

Смирнов А.А. Гижигинско-камчатская сельдь : моногр. - Магадан : МагаданНИРО, 2009. - $149 \mathrm{c}$.

Шунтов В.П. Современный статус биологических ресурсов Охотского моря // Рыб. хоз-во. - 1998. - № 4. - С. 40-42.

Шунтов В.П., Волвенко И.В., Волков А.Ф. и др. Новые данные о состоянии пелагических экосистем Охотского и Японского морей // Изв. ТИНРО. — 1998. — Т. 124. — С. 139-177.

\section{References}

Volvenko, I.V., Some algorhythms of data processing on abundance and size-weight structure of catches, Izv. Tikhookean. Nauchno-Issled. Inst. Rybn. Khoz. Okeanogr., 1999, vol. 126, pp. 177-195.

Melnikov, I.V., Results of estimation of herring stock in the northern part of the Okhotsk Sea by trawl surveys in 2000, Izv. Tikhookean. Nauchno-Issled. Inst. Rybn. Khoz. Okeanogr., 2002, vol. 130 , pp. 1142-1158.

Naumenko, N.I., Biologiya i promysel morskikh sel'dei Dal'nego Vostoka (Biology and Harvesting of Sea Herring in the Far East), Petropavlovsk-Kamchatsky: Kamchatsky Pechatny Dvor, 2001.

Smirnov, A.A., Gizhiginsko-kamchatskaya sel'd' (The Gizhigin-Kamchatka Herring), Magadan: MagadanNIRO, 2009. - $149 \mathrm{c}$.

Shuntov, V.P., The current status of biological resources in the Sea of Okhotsk, Rybn. Khoz., 1998, no. 4, pp. 40-42.

Shuntov, V.P., Volvenko, I.V., Volkov, A.F., Gorbatenko, K.M., Shershenkov, S.Yu., and Starovoitov, A.N., New data about condition of pelagic ecosystems of the Okhotsk and Japan Seas, Izv. Tikhookean. Nauchno-Issled. Inst. Rybn. Khoz. Okeanogr., 1998, vol. 124, pp. 139-177.

Nagul'naya sel'd'-2017 (putinnyi prognoz) (Feeding Herring 2017 (Prediction of the Fishing Season)), Vladivostok: TINRO-Tsentr, 2017.

Поступила в редакичию 13.08.2018 2.

После доработки 20.08.2018 г.

Принята к публикациии 11.10.2018 г. 